
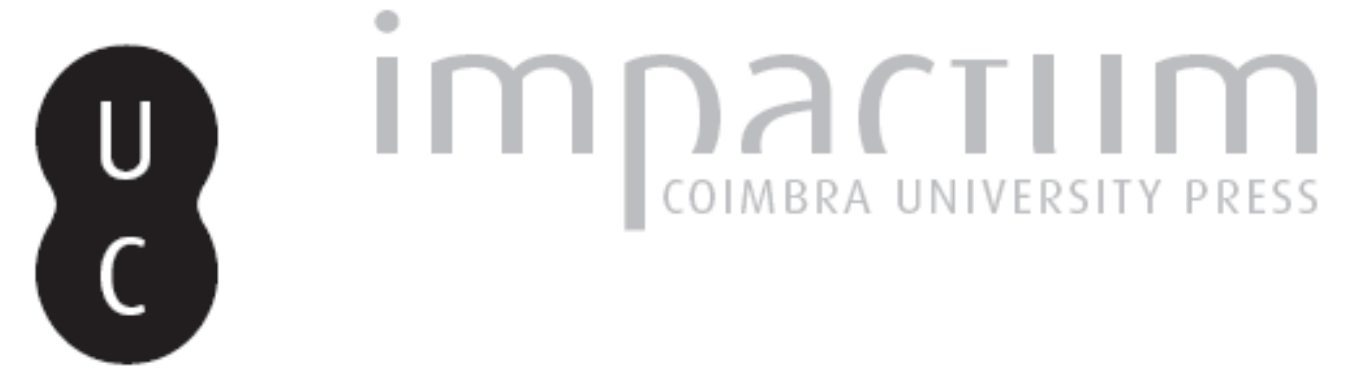

\title{
Televisão e império: sobre a inexistência de emissões da RTP nas províncias ultramarinas portuguesas
}

\author{
Autor(es): $\quad$ Cádima, Francisco Rui
}

Publicado por: Imprensa da Universidade de Coimbra

URL persistente:

URl:http://hdl.handle.net/10316.2/39631

DOI:

DOI:http://dx.doi.org/10.14195/2183-5462_29_5

Accessed : $\quad$ 26-Apr-2023 14:29:13

A navegação consulta e descarregamento dos títulos inseridos nas Bibliotecas Digitais UC Digitalis, UC Pombalina e UC Impactum, pressupõem a aceitação plena e sem reservas dos Termos e Condições de Uso destas Bibliotecas Digitais, disponíveis em https://digitalis.uc.pt/pt-pt/termos.

Conforme exposto nos referidos Termos e Condições de Uso, o descarregamento de títulos de acesso restrito requer uma licença válida de autorização devendo o utilizador aceder ao(s) documento(s) a partir de um endereço de IP da instituição detentora da supramencionada licença.

Ao utilizador é apenas permitido o descarregamento para uso pessoal, pelo que o emprego do(s) título(s) descarregado(s) para outro fim, designadamente comercial, carece de autorização do respetivo autor ou editor da obra.

Na medida em que todas as obras da UC Digitalis se encontram protegidas pelo Código do Direito de Autor e Direitos Conexos e demais legislação aplicável, toda a cópia, parcial ou total, deste documento, nos casos em que é legalmente admitida, deverá conter ou fazer-se acompanhar por este aviso.

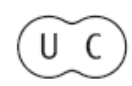




\section{Media Jornalismo}

\section{MÉDIA E COLONIALISMO(S)}




\title{
TELEVISÃO E IMPÉRIO: SOBRE A INEXISTÊNCIA DE \\ EMISSÕES DA RTP NAS PROVÍNCIAS \\ ULTRAMARINAS PORTUGUESAS
}

\section{TELEVISION AND EMPIRE: ON THE ABSENCE OF EMISSIONS OF THE PORTUGUESE TELEVISION STATION IN THE OVERSEAS PROVINCES}

\section{FRANCISCO RUI CÁDIMA}

UNIVERSIDADE NOVA DE LISBOA/ FACULDADE DE CIÊNCIAS SOCIAIS E HUMANAS/

CIC.DIGITAL E DEPARTAMENTO DE CIÊNCIAS DA COMUNICAÇÃO

1069-061 LISB0A - PORTUGAL

FRCADIMA@GMAIL.COM

\begin{abstract}
Resumo
Neste texto vamos procurar entender algumas das razões fundamentais que explicam o facto de a televisão nunca ter chegado às colónias portuguesas, quer durante a governação de Salazar, quer inclusivamente com Marcello Caetano, apesar de ter sido ele o impulsionador da televisão em Portugal. Da análise do contexto político nacional e internacional e do confronto com a própria experiência sul-africana, mais determinada na sua "iconoclastia" catódica, algumas das conclusões que retiramos conduzem-nos a uma pergunta para a qual a própria experiência política e mediática do apartheid parece sugerir uma resposta. E que tem a ver com os impactos possíveis de uma outra estratégia propagandística televisiva em contexto colonial. Que consequências diversas poderia ter tido? Deixemos que seja aqui o próprio leitor a retirar as suas conclusões.
\end{abstract}

\section{Palavras-chave \\ Televisão, Salazarismo, Ditadura, Colónias}

\section{Abstract}

In this text we will try to understand some of the fundamental reasons for the fact that television never reached the Portuguese colonies, either during the government of Salazar or even with Marcello Caetano, although he was the promoter of television in Portugal. The analysis of national and international political context and the confrontation with the South African own experience, more determined in its "cathodic iconoclasm", some of the conclusions we draw lead us to a question that the very political and media experience of apartheid seems to suggest an answer. And that has to do with the possible impacts of another television propaganda strategy in the colonial context. What diverse consequences could that have had? Let the reader be here him or herself to withdraw its conclusions.

Television, Salazarism, Dictatorship, Colonies 
INTRODUÇÃO

Os estudos no âmbito da história dos média em Portugal têm vindo a desenvolver-se de forma consistente nas últimas décadas, notando-se agora um renovado interesse por uma área menos investigada, justamente em torno da questão dos média e da experiência colonial, de que, aliás, este volume é prova. A nossa opção para esta breve investigação incide sobre um aspeto muito particular, que, porventura pelo facto de se tratar, de alguma forma, de um "não-acontecimento" no contexto das relações do regime com as suas colónias, não tem sido praticamente referido nos estudos da área.

Trata-se, então, de procurar contextualizar o facto do salazar-caetanismo e das políticas do regime para o sector dos média terem, desde 0 final dos anos 50 , várias vezes pensado em instalar as emissões televisivas regulares nas ditas províncias ultramarinas, sem nunca o terem conseguido efetivamente concretizar. É então sobre todo este percurso, sobre a genealogia e as razões desse mesmo "não-acontecimento" - que aliás acompanha praticamente toda a própria história da televisão em Portugal - que incide esta investigação.

Com exceção da complexa dinâmica propagandística criada na RTP na sequência do início das hostilidades em Angola, em 1961, dando-se assim origem à Guerra Colonial, a relação do regime do Estado Novo com o "império", mais propriamente com as suas províncias ultramarinas "integradas" no todo nacional desde a revisão constitucional de 1951, foi, por assim dizer, um sinal de que, sobretudo Salazar, nunca esteve suficientemente convencido de que o elevado investimento financeiro e tecnológico numa rede de distribuição de televisão em África se justificaria verdadeiramente.

Isto porque, certamente, o regime salazarista não tinha essa convicção profunda de que à então África portuguesa sucederia o contrário daquilo que nos inícios dos anos 60 tinha ocorrido com todas as colónias africanas das potências europeias -a sua autonomia e/ou independência. Esta talvez possa ser uma das explicações mais prováveis, forçada pelas próprias circunstâncias políticas - sobretudo pela questão do esforço de guerra - e económico-financeiras do regime, para o facto de a televisão da metrópole - a RTP - não ter chegado nunca às províncias ultramarinas.

\section{RESISTÊNCIAS AO NOVO MEIO TELEVISIVO}

Digamos que podemos identificar essa razão "política", por assim dizer, mas não podemos evitar discutir uma outra razão complementar desta. Concretamente, no plano comunicacional, a questão do receio do impacto da imagem televisiva num contexto de forte controlo político e mediático por parte da potência colonial. Contexto que, no plano da política internacional era absolutamente desfavorável ao salazarismo. E isto tanto no plano externo, com as grandes nações europeias a abdicarem das suas colónias africanas e as organizações internacionais a pressionarem o governo português a fazer o mesmo, como no plano interno, com a cada vez maior oposição ao regime na metrópole e 0 arranque dos conflitos bélicos nas diversas províncias ultramarinas.

De facto, esse receio por um muito provável descontrolo sobre as imagens televisivas num contexto de opressão colonial, ainda que nunca tenha sido enunciado enquanto tal pelos responsáveis do regime, teria seguramente sido ponderado. Sa- 
bemos, efetivamente, que Salazar sempre havia mostrado a maior das relutâncias em relação à introdução da televisão em Portugal, que nunca se serviu realmente da televisão como um instrumento pessoal de propaganda, bem pelo contrário, e que, portanto, nunca seria, sem uma mudança radical da sua perceção sobre o fenómeno televisivo, que ele soçobraria ao seu convencimento profundo de que os meios de comunicação de excelência sempre seriam, para si, a imprensa e a rádio. E esses eram - e sempre foram -, mesmo com Marcelo Caetano, os meios dominantes na África portuguesa até 1974. Tal como, aliás, viria a suceder curiosamente no caso da África do Sul, nos anos 60, como veremos de seguida.

0 caso português, em matéria de resistência e impedimento político ao avanço comunicacional e tecnológico só tinha de facto equiparação, na altura, ao caso sul-africano. Veja-se como termo de comparação o que sucedia na altura no regime do apartheid. Este caso é, aliás, paradigmático no âmbito da história dos média e dos estudos televisivos. Ao longo dos anos 60 , havia, aliás, uma perceção evidente, por parte das forças nacionalistas - e neste caso claramente enunciada - de que o início das emissões regulares de televisão na África do Sul conduziria rapidamente ao declínio do poder branco nesse país, tendo o novo meio de comunicação sido transformado no verdadeiro "arqui-inimigo" dos interesses Afrikaner e da sua política ultra-conservadora. Para além do mais, na perspetiva do regime do apartheid, mesmo a programação ocidental podia ser extremamente negativa para os interesses nacionalistas:

British and American programmes were not advisable, particularly at the time of the Civil Rights movement in the USA. It would not be a good thing to see all those Blacks rioting and confronting police forces on the streets of Little Rock, Arkansas, and Birmingham, Alabama, when South Africa's government was advocating co-operation and peaceful separate development of races. (Cros, 1996: 121)

A ideologia da extrema-direita sul-africana, ultra-nacionalista e calvinista, procurava teorizar sobre 0 tema dos perigos da televisão e sobre as consequências imprevisíveis da sua adoção. No início dos anos 60 , um dos principais argumentos utilizados era o facto de a TV poder afastar as pessoas da igreja, 0 que poria em perigo a sobrevivência da tradição afrikaner, desviando a atenção dos seus membros para outras referências culturais que Ihes seriam estranhas. Pelo contrário, a rádio era considerada ajustada ao modelo vigente de uma sociedade de apartheid. A televisão era vista também como um perigo moral para a família e a juventude. Também era utilizado o argumento do "efeito hipnótico" sobre o público. Mas a obsessão ultra-conservadora atingia as raias do paroxismo quando pretendia que a influência liberal americana ou europeia poderia ter efeitos tão perversos na velha cultura afrikaner quanto o próprio "imperialismo comunista", ou poderia inclusive conduzir ao fim do domínio branco:

TV would bring political integration which would, in turn, bring 'the end of the Western civilisation in South Africa, the political eclipse of Whites and everything they have built up over a period of more than 300 years (Giliomee, 1990:42, apud Cros 1996:124). 
Realmente, a África do Sul só em janeiro de 1976 viria a iniciar as emissões regulares de televisão, sendo que a transição para uma informação aberta e plural não se fez sem muitas hesitações e continuados receios ao longo dos anos 80 (Cádima, 1995), como aliás se pode ver através do caso Nelson Mandela (Tomaselli, 1993 e 2003), que só viria a ser libertado pelas autoridades sul-africanas em 1990. No caso sul-africano, são os próprios líderes políticos da altura, nomeadamente o primeiro-ministro Hendrik Verwoerd, que fazia comparações dramáticas considerando que a televisão teria efeitos nefastos na sociedade sul-africana e que seria pior que a bomba atómica, invocando aqui a célebre "boutade" de John Appleton, responsável em meados dos anos 50 pelos programas para crianças na Australian Broadcasting Commission. Ou o ministro das telecomunicações, Albert Hertzog (conhecido então como Dr. No), que postulava que a TV era algo incontrolável e que se alguém pretendesse introduzir a televisão na África do Sul, só mesmo por cima do seu cadáver isso seria possível... No fundo, tudo se resumia a ver o pequeno écran como uma "devil's own box, for disseminating communism and immorality".

\section{TENTATIVAS ABORTADAS}

Voltando ao caso português, refira-se que não sendo conhecidos documentos escritos em que o regime se tenha colocado o mesmo tipo de questões e argumentos que os conservadores sul-africanos esgrimiam por essa altura, a verdade é que, na prática, e certamente, em teoria, por algumas das mesmas razões em ambos os casos, os resultados foram os mesmos, isto é, a televisão só chegaria aos países africanos de expressão portuguesa após as independências concedidas por Portugal no pós-25 de Abril.

A resistência do regime ao investimento na tecnologia televisiva para as províncias ultramarinas tinha aliás uma outra face no plano do consumo interno. E essa manifestava-se, concretamente, em termos de programação e de informação na RTP, a televisão entretanto surgida em Portugal em 1957, após, como referimos, Salazar ter resistido ainda por alguns anos à sua instalação no país (Cádima, 1996). Mas do que se tratava era essencialmente de uma quase ausência absoluta da imagem das províncias ultramarinas, em particular nos serviços noticiosos. Onde o "bilhete-postal" turístico poderia coexistir com a agenda protocolar governamental na metrópole, ou um mercado popular, ou uma festa de folclore local, poderiam ser mostradas no final do alinhamento de um qualquer telejornal.

Temos, portanto, uma dupla situação, convergente com um mesmo tipo de ação política relativamente às colónias: por um lado, a ausência demasiado ostensiva de uma imagem televisiva do império e das colónias, designadamente no que reporta ao essencial das práticas informativas: nem cobertura regular dos principais acontecimentos nas diferentes províncias, nem correspondentes locais enviando notícias e reportagens para Lisboa, nem em geral o contrário, o envio de repórteres da metrópole para cobrir eventos locais, fazer reportagem ou documentários sobre

1 "From devil's box to diversity: 30 years of SABC television" (2007). Mybroadband, January 7 , 2007. http://mybroadband.co.za/nephp/5299.html. Acedido a 13 de junho de 2016. 
a realidade das colónias; por outro lado, 0 adiamento da instalação da televisão nas províncias ultramarinas, o que se viria a eternizar ao longo do tempo, tendo 0 regime caído sem ter conseguido dar esse passo. E isto, não porque os ideólogos do regime não tivessem a noção da importância da comunicação e da necessidade de uma estratégia mediática que acompanhasse efetivamente o modelo integrador e pluricontinental do regime. Veja-se, por exemplo, sobre esse aspeto, Clemente Rogeiro (1971: 60): "( ...) Urge repensar toda a estrutura das nossas telecomunicações, conscientes de que, na era da eletrónica já iniciada, dispomos de meios para superar a descontinuidade territorial em que vivemos e para sermos, finalmente, a nação una e indivisível a que aspiramos".

Refira-se, por exemplo, que pouco após o arranque das emissões televisivas da RTP, há uma primeira decisão sobre a estratégia de implantação do serviço de televisão nas colónias. Em 1959, numa altura em que a instalação da rede de distribuição em Portugal não estava ainda concluída, havendo ainda poucos recetores registados, não havendo sequer rede na Madeira e nos Açores, são dados os primeiros passos para a instalação da televisão em Angola e Moçambique (Cádima, 1996), conforme é dito também no Relatório e Contas da RTP de 1959:

Mais do que nunca a ideia de estender a nossa atividade às Províncias Ultramarinas parece impor-se como uma necessidade da maior importância e, pela nossa parte, temos o problema estudado. As comparticipações necessárias encontram-se, na sua maioria, asseguradas e a fórmula encontrada é muito pouco dispendiosa em relação às vantagens que proporciona. ${ }^{2}$

0 que é interessante verificar é que essa primeira manifestação de interesse no final dos anos 50, tão claramente afirmativa, garantindo inclusive o financiamento da operação, passa rapidamente ao esquecimento, e durante a década de 60 pouco mais será dito sobre 0 assunto. Veja-se que no início da década de 70, o regime está a braços sobretudo com o lançamento da televisão na Madeira e Açores. No caso da Madeira, a inauguração das emissões aconteceria somente a 6 de agosto de 1972. Dizia-se na altura que se iniciava deste modo um "objetivo expansionista" tratando-se agora apenas do primeiro serviço que se implantava "fora de território metropolitano e que poderá muito bem ser (...) o ponto de partida para a interligação do espaço português sob o signo da TV (...)" (Teves e Lopes da Silva, 1971: 186).

Estranhamente, no caso dos Açores, só a 10 de agosto de 1975, já em plena democracia, iriam para 0 ar as primeiras emissões de televisão naquele arquipélago. Apesar do atraso de três anos em relação à Madeira, a televisão chegou aos Açores mais cedo do que se previra e sobretudo porque Ramalho Eanes, na altura Presidente da RTP, no final de 1974, muito se empenhou pessoalmente (Teves, 2007: 127) em resolver esse imbróglio.

Mais estranhamente ainda, não estava sequer resolvido o problema das emissões regulares de televisão nos Açores e já se faziam promessas para Angola... 0 que veio criar uma situação particularmente desagradável, sobretudo para os

2 Relatório e Contas da RTP de 1959, pp. 5-6. 
açorianos que se viam assim discriminados relativamente à pressão que vinha de determinados estratos da sociedade angolana, onde os meios de comunicação, sobretudo a Rádio, tinham um leque de profissionais que acabaram por fazer escola nos media em Portugal no pós-25 de Abril. E entre os açorianos estava o próprio presidente da RTP, Ramiro Valadão... No fundo, era claro que o regime não tinha capacidade financeira para acudir a tantas solicitações. Isso aliás já havia sido bem enunciado nos anos 60 por um Diretor-Geral da RTP, Barradas de Carvalho (1963: 194), que não podia ser mais claro: "Uma organização de televisão como a RTP, modestíssima até à miséria em alguns sectores, mesmo defendida das despesas inúteis que as próprias limitações determinam (...)", não poderia certamente "expandir-se", e a prova disso foi exatamente o atraso do arranque da televisão na Madeira e Açores, e, claro, o sempre adiado começo nas colónias. Queixa que Ramiro Valadão (1971: 81-82) secundaria mais tarde, embora de forma mais discreta, considerando ser necessário um "esforço que ultrapasse a nossa dimensão para nos colocar na que resulta da nossa responsabilidade pluricontinental", sendo que "para quem, como nós, importa defender Portugal em vários continentes, temos de ter ao nosso dispor meios mais potentes que os demais".

\section{UMA DECISÃO DEMASIADO TARDIA}

É justamente já em pleno declínio do regime, em 1973, que vamos ter novidades sobre o tema, antecipadas agora pelo Ministério do Ultramar. Em 27 de junho de 1973 é publicado pelo ministro do Ultramar, Silva Cunha, o Decreto-Lei $n^{0}$ 319/73 que vem permitir ao Governo promover "a constituição de empresas para a concessão do serviço público de televisão nos territórios de cada uma das províncias ultramarinas". Diz-se que ouvidos os governos das províncias ultramarinas, a RTP deverá promover a constituição de sociedades anónimas com as quais contratará a concessão do serviço público de televisão nos respetivos territórios, podendo mesmo ser a própria RTP a assumir a exploração do serviço, sendo que a percentagem do capital a repartir entre o Governo da correspondente província e a RTP nunca seria inferior a $51 \%$, sendo o restante distribuído pela radiodifusão local e pelo público, em proporção a determinar em cada contrato de concessão. A detenção de aparelhos recetores de televisão obrigava ao pagamento da taxa de televisão.

Nas Bases de concessão, era referido que a concessionária era obrigada a instalar de acordo com os planos e prazos aprovados pelo governador da província, os respetivos centros de emissão e/ou de distribuição nas regiões de "maior interesse", tendo também em vista "o interesse manifestado pelo público". A concessão era dada por um período de dez anos. Na Base VII salvaguardava-se a ligação à RTP no sentido do estabelecimento de acordos de colaboração e interdependência com vista a assegurar a obtenção das "maiores economias de escala". Finalmente a Base X conferia o direito de suspensão do serviço: "sempre que as circunstâncias assim 0 aconselhem, designadamente em caso de guerra ou de emergência grave, (o governo) reserva-se o direito de suspender, por tempo indeterminado, o serviço concedido" e a Base XIV prescrevia que a "fiscalização em relação aos serviços concedidos será exercida por um delegado do Governo", ou seja, "quanto a programas", serão os serviços designados para o efeito pelo Governador da província que zelarão 
pelo seu adequado cumprimento. Em caso limite - Base XVI, poderia o Governador da província, mediante autorização do ministro do Ultramar, substituir-se temporariamente à concessionária, "declarando a concessão em estado de sequestro".

De referir ainda um outro diploma sobre 0 tema, 0 Decreto-Lei $n^{0}$ 381/73, de 26 de julho, também do Ministério do Ultramar, que vem aprovar as normas técnicas "a que deveriam obedecer as instalações do serviço público de televisão a preto e branco" (Artigo 1.9) nas províncias ultramarinas, de acordo com o estabelecido na Conferência Africana de Radiodifusão (Genebra-1963) que atribuiu às províncias ultramarinas portuguesas o sistema «l» (bandas I, III, IV e V) para as respetivas redes de televisão. No Artigo 2. ${ }^{\circ}$ deste decreto promulgado por Américo Thomaz em 9 de julho de 1973, era ainda referido que as normas para as "províncias ultramarinas portuguesas da Ásia e da Oceânia e as normas técnicas a que deverão obedecer as instalações do serviço público de televisão a cores em todos os territórios portugueses do ultramar" seriam oportunamente aprovadas.

Por fim, já após o 25 de Abril, referência ainda para um outro Decreto-Lei, 0 $677 / 74$, de 29 de novembro, que aprova as bases relativas à concessão do serviço público de televisão em Angola. No preâmbulo remete-se para o Decreto-Lei 319/73 (revogando este, na parte aplicável a Angola), que autorizava o Governo a promover com a RTP a constituição de sociedades anónimas para a exploração do serviço público de televisão. Constatava o governo de Vasco Gonçalves, através do ministro da Coordenação Interterritorial, António de Almeida Santos, que o referido decreto-lei se revestia "de uma feição demasiado centralizadora, nomeadamente no que se refere à vinculação obrigatória à RTP" pelo que havia que publicar novo diploma em concordância com as normas previstas para o futuro estatuto político de Angola. Assim, o Governo Provisório usando a faculdade conferida pela Lei Constitucional 3/74, decretava "para valer como lei no ultramar" o seguinte (Artigo 1. ${ }^{\circ}$ ): "0 Governo de Angola (...) promoverá a constituição de uma sociedade anónima de responsabilidade limitada com a qual contratará a concessão do serviço público de televisão em Angola, nos termos das bases anexas a este diploma", sendo que 0 capital da sociedade será distribuído de forma a que uma percentagem não inferior a $51 \%$ pertença ao Governo de Angola. 0 Artigo 3. ${ }^{\circ}$ prescrevia, no entanto, que "os corpos gerentes da sociedade concessionária do serviço público considerada neste diploma serão constituídos, exclusivamente, por cidadãos portugueses originários ou naturalizados há mais de dez anos". As questões do foro jurídico remetiam, no entanto, para um tribunal arbitral no âmbito do Tribunal da Relação de Luanda.

No caso angolano, curiosamente, são referidas por algumas fontes breves tentativas experimentais de lançamento de emissões televisivas, embora num plano muito rudimentar e, naturalmente, à revelia da própria administração colonial. São comummente referidos os casos das emissões no Rádio Clube de Huambo, em 1962, no Rádio Clube de Benguela em 1964, na discoteca Tamar, em Luanda, em junho de 1970, e da TVA, em Luanda, em 1973, projeto independente onde pontificavam inclusivamente antigos colaboradores da própria RTP, e que terá sido responsável pela aprovação urgente, por parte do governo de Marcello Caetano, do já referido decreto-lei 319/73.

Após, portanto, em 1973, 0 Governo português ter lançado com este decreto as bases daquela que seria a concessionária da radiotelevisão de Angola, é constituída 
em fevereiro de 1974, a RPA - Radiotelevisão Portuguesa de Angola, tendo como acionistas maioritários o Estado de Angola, o Instituto de Crédito de Angola, a RTP e várias estações de rádios locais que repartiam entre si 25\% do capital (Teves, 2007a). No entanto, face ao novo regime de transição política entretanto criado, 0 governo português vê necessidade de revogar o decreto de 1973, o que sucede com o 677/74 a 29 de novembro de 1974, precisamente no sentido de permitir um serviço público de televisão em Angola mais autonomizado, não dependente da RTP. É assim que o governo de transição em Angola lança as emissões regulares de televisão a 18 de outubro de 1975. Após a independência, concretizada em 11 de novembro de 1975, o governo do MPLA nacionaliza a concessionária em junho de 1976 e introduz a alteração na sua designação passando esta a chamar-se TPA - Televisão Popular de Angola. Mais tarde, em setembro de 1997, alterada, por sua vez, para empresa pública, agora designada Televisão Pública de Angola.

\section{Conclusões}

Em conclusão, é então possível constatar que existem, à partida, várias causas que poderemos identificar como tendo estado na origem deste "não-acontecimento" no contexto da experiência mediática das colónias portuguesas. Desde logo, uma razão de ordem económica-financeira, invocada, em diversos momentos, por responsáveis máximos da RTP, questão que terá tido um papel importante no adiar da experiência televisiva e da implementação desta tecnologia nas colónias. Há, depois, uma razão política e, digamos, também mediática, comunicacional, que é fundamentalmente identificada através dos escassos conteúdos emitidos (notícias, reportagens, breves documentários) relativos às províncias ultramarinas, e que, sobretudo no período que decorre entre o início das emissões regulares e o início da Guerra Colonial, não apresentavam qualquer consistência narrativa, nem no plano jornalístico, nem tão pouco no plano propagandístico, demonstrando assim a inépcia do regime em matéria de instrumentalização da televisão para os seus objetivos políticos.

A acrescentar à falta de motivação propagandística, instrumental e política no início das emissões televisivas da RTP, até ao começa da Guerra Colonial explicadas nas fobias do ditador em relação ao novo media mas que significava também um desconhecimento das virtualidades do próprio meio em si, há ainda a considerar a questão do "destino das grandes províncias africanas de Angola e Moçambique", ou seja, as hesitações autonomistas e federalistas que por essa altura inquietariam tanto Salazar como Marcello Caetano (1977:516), então seu ministro da presidência, mas que rapidamente levariam o ditador à obsessão pela política de integração. 0 próprio início da Guerra Colonial, a mobilização do regime na manutenção do "todo pluricontinental" e o esforço financeiro e de guerra num conflito de longa duração que se desenvolvia em múltiplas frentes, também vieram colocar a questão das emissões televisivas nas colónias fora da agenda do regime. E assim permaneceriam até final. Com alguma ironia da história, o próprio "fundador" da RTP, Marcello Caetano, apesar da sua forte convicção nas capacidades instrumentais da televisão, não conseguiu muito mais do que apenas elaborar o decreto-lei (319/73, de 27 de junho) com vista à concessão do serviço público de televisão nas colónias. E, mesmo assim, sem consequências. 
Bibliografia

Barradas da Silva (1963). "O jornalismo e os modernos meios audiovisuais", Revista de

Ciências Políticas e Sociais, Junta de Investigações do Ultramar, n60, pp. 177-199.

Caetano, Marcello (1977). Minhas memórias de Salazar. Lisboa: Verbo.

Cros, Bernard (1996) "Why South Africa's Television is only Twenty Years Old: Debating Civilisation", 1958-1969. Alizés, Revue Angliciste de la Réunion, n 12, "Taboos", October 1996, pp. 117-130. http://oracle-reunion.pagesperso-orange.fr/documents/217.html.

Cádima, F. Rui (1995). O Fenómeno Televisivo, Lisboa: Círculo de Leitores.

Cádima, F. Rui (1996). Salazar, Caetano e a Televisão Portuguesa. Lisboa: Presença.

Decreto-Lei n ${ }^{0}$ 319/73, de 27 de junho. Ministério do Ultramar - Direcção-Geral de Obras Públicas e Comunicações. Diário do Governo n. ${ }^{0}$ 149/1973, Série I de 1973-06-27.

Decreto-Lei n ${ }^{0}$ 381/73, de 26 de julho. Ministério do Ultramar - Direcção-Geral de Obras Públicas e Comunicações. Diário do Governo n. ${ }^{0}$ 174/1973, Série I de 1973-07-26.

Decreto-Lei n ${ }^{0}$ 677/74, de 29 de novembro. Ministério da Coordenação Interterritorial. Diário do Governo n. ${ }^{0}$ 278/1974, $1^{0}$ Suplemento, Série I de 1974-11-29.

"From devil's box to diversity: 30 years of SABC television" (2007). Mybroadband, January

7, 2007. http://mybroadband.co.za/nephp/5299.html. Acedido a 13 de junho de 2016.

Giliomee, H. e Lawrence (1990). From Apartheid to Nation-Building. 2nd ed. (Cape Town: Oxford UP, 1990).

"Início da Televisão em Angola" (s/d). Radiodifusão em Angola (1937/1975). http:// angolaradio.webs.com/. Acedido em 14 de junho de 2016.

Relatório e Contas da RTP (1959). Lisboa: RTP.

Rogeiro, Clemente (1971). "A Rádio, factor de unidade nacional". AAVV, Problemática Na-

cional da Informação. Textos das conferências proferidas no Instituto de Altos Estudos Militares. Lisboa, 1971, pp. 37-69.

Teves, Vasco (2007). RTP - 50 anos de história. Lisboa: RTP.

Teves, Vasco (2007a). RTP - 50 anos de história (versão integral em CD) Lisboa: RTP.

Teves, Vasco e Lopes da Silva, M. J. (1971). Vamos falar de Televisão. Lisboa: Livros RTP.

Tomaselli, Keyan \& Boster, Bob (1993). "Mandela, MTV, Television and apartheid", Popular Music and Society, Volume 17, Issue 2, 1993, pages 1-19. D0l:10.1080/03007769308591510. Tomaselli, Keyan \& Tomaselli, Ruth (2003) "The Media and Mandela", Safundi: The Journal of South African and American Studies, 4:2, 1-10, D0I: 10.1080/17533170300404204 Torres, Sílvia (2016) (Org.). O Jornalismo Português e a Guerra Colonial. Lisboa: Guerra e Paz. Valadão, Ramiro (1971). "Problemática da Televisão". AAVV, Problemática Nacional da Informação. Textos das conferências proferidas no Instituto de Altos Estudos Militares. Lisboa, 1971, pp. 71-83. 